\title{
Efeitos dos pulsos de inundação na vegetação do alto Rio Paraná entre 1989 e 1990
}

O avanço da tecnologia permitiu que estudos em áreas pudessem ocorrer remotamente, como em planícies de inundação, pois este ambiente é de difícil acesso. A planície de inundação do Alto Rio Paraná é um ambiente diverso em vegetação possuindo mais de 360 espécies, as quais são controladas pelos pulsos de inundação e devido a sua importância ecológica estudos relacionados a influência da inundação sobre a vegetação, faz-se necessário. Com isso, o objetivo deste trabalho é estudar a influência que a inundação da planície do Alto Rio Paraná, causa sobre a vegetação para o pulso do ano de 1989/1990. Utilizando-se de imagens de satélite e índices de vegetação foi realizado a classificação do uso do solo antes e após o pulso com as classes de água, solo exposto, vegetações higrófilas, herbáceas e arbóreas. Verificou-se que, após a inundação as vegetações higrófilas, arbóreas e solo exposto diminuíram. No entanto, as áreas de vegetação herbácea e água aumentaram, e isto ocorre devido às classes que foram reduzidas preferirem ambientes com sedimentos; referindo-se às que aumentaram, foi devido à baixa capacidade de infiltração do solo. Dessa forma, conclui-se que a inundação da planície afetou na dinâmica da vegetação reduzindo ou ampliando a área de ocorrência dos tipos vegetacionais.

\section{Effects of flood pulses on upper Paraná River vegetation between 1989 and 1990}

\begin{abstract}
Advances in technology have allowed studies in areas to occur remotely, such as flood plains, as this environment is difficult to access. The Upper Paraná River floodplain is a diverse vegetation environment with more than 360 species, which are controlled by flood pulses and due to its ecological importance studies related to the influence of flooding on vegetation are required. Thus, the objective of this work is to study the influence that flooding of the Upper Paraná River plain has on the vegetation for the 1989/1990 pulse. Using satellite images and vegetation indices, land use classification was performed before and after the pulse with the classes of water, exposed soil, hygrophilous, herbaceous and arboreal vegetation. After flooding, hygrophilous, arboreal and exposed soil decreased. However, the areas of herbaceous vegetation and water increased, and this is due to the fact that the reduced classes prefer sediment environments; referring to those that increased, it was due to the low infiltration capacity of the soil. Thus, it is concluded that the flooding of the plain affected the dynamics of vegetation by reducing or increasing the area of occurrence of vegetation types.
\end{abstract}

Keywords: Flood plain; Vegetational dynamics; Influence of floods and ebb.

Topic: Tecnologia, Modelagem e Geoprocessamento

Reviewed anonymously in the process of blind peer.

Renata Mariane de Souza

Universidade Estadual de Maringá, Brasil

http://lattes.cnpq.br/4830374616462752

renatamarianee@gmail.com

Leonardo da Silva Tomadon (iD

Universidade Tecnológica Federal do Paraná, Brasil

http://lattes.cnpq.br/9269578340655258

http://orcid.org/0000-0003-0332-7896

leonardotomadon@hotmail.com

Edivando Vitor do Couto

Universidade Tecnológica Federal do Paraná, Brasil

http://lattes.cnpq.br/3716500436905139

http://orcid.org/0000-0003-4264-8449

edivandocouto@gmail.com
Received: 18/10/2018

Approved: $20 / 11 / 2018$
José Hilário Delconte Ferreira

Universidade Tecnológica Federal do Paraná, Brasil

http://lattes.cnpq.br/5085571914463442

jhdferreira@gmail.com

\section{Referencing this:}

SOUZA, R. M.; TOMADON, L. S.; COUTO, E. V.; FERREIRA, J. H.. Efeitos dos pulsos de inundação na vegetação do alto Rio Paraná entre 1989 e 1990. Revista Ibero-Americana de Ciências Ambientais, v.9, n.8, p.299-309, 2018. DOI: http://doi.org/10.6008/CBPC2179$\underline{6858.2018 .008 .0026}$

DOI: 10.6008/CBPC2179-6858.2018.008.0026 


\section{INTRODUÇÃO}

Com o avanço da tecnologia e o progresso das áreas de telecomunicações, ciência da computação, mecânica fina de precisão, óptica de precisão, entre outras áreas, desenvolveram-se as técnicas de sensoriamento remoto. Atualmente, há uma gama de aplicações dessas técnicas, principalmente para estudos do meio ambiente, como os relacionados à agricultura, geologia, pedologia, geomorfologia, relevo, recursos hídricos, vegetação (JENSEN, 2009).

Aproximadamente $70 \%$ da superfície terrestre é recoberta de vegetação. Desta maneira, ao longo dos últimos anos, foram desenvolvidas diferentes técnicas de sensoriamento remoto para conhecer as variações das espécies, dos padrões de distribuição das comunidades vegetais, alterações dos ciclos fenológicos. Muitas das técnicas empregadas podem ser aplicadas a diferentes paisagens vegetadas, e.g. agricultura, florestas, pastagens nativas, planícies de inundação, vegetação urbana. Dentre os diferentes tipos de técnicas, destacam-se os índices de vegetação, que auxiliam na avaliação, monitoramento e detecção de mudanças no meio ambiente (JENSEN, 2009; MARCUSSI et al., 2010).

Há diversos índices de vegetação, entre eles, o Normalized Difference Vegetation Index (NDVI), Modified Soil-adjusted Vegetation Index (MSAVI) e o Normalized Difference Moisture Index (NDMI). O NDVI é um índice utilizado para monitorar a produção de biomassa na vegetação (ROUSE JUNIOR et al., 1974). Porém, segundo Rondeaux et al. (1996), o NDVI é sensível a fatores externos, como: energia solar, geometria de visualização, solo presente ao fundo das imagens, variações do substrato do dossel e aos efeitos atmosféricos. Com isso, o MSAVI surge como um índice que prioriza a dinâmica da vegetação, minimizando os efeitos do solo (QI et al., 1994). Já o NDMI está associado ao teor de umidade na vegetação, ou seja, o índice é sensível a pequenas mudanças nas condições de umidade da vegetação (JENSEN, 2009).

Segundo um trabalho realizado por Fragal et al. (2011), que compara imagens que tiveram classificação automática com base em índices de vegetação, como NDVI e AFRI, com imagens cuja classificação foi baseada na interpretação visual, Fragal et al. (2011) mostrou que a classificação por interpretação visual teve ótima precisão quanto as baseadas em índices de vegetação, obteve-se um índice de Kappa de 0,4632 e 0,3759 para o NDVI e o AFRI, respectivamente.

O coeficiente de Kappa é um dos índices utilizados para avaliar a acurácia, ou seja, a confiabilidade e exatidão da classificação de imagens (FIGUEIREDO et al., 2007). Contudo, a interpretação visual pode vir associada à subjetividade de informação pelo observador. Desta forma, avaliando apenas a classificação automática mostra-se que o NDVI foi o índice que apresentou melhor exatidão da classificação.

Fragal et al. (2012) utiliza-se de todas as bandas exceto a banda 6 (infratermal) para a classificação das imagens; já para Souza Filho et al. (2013), a classificação foi feita com todas as bandas, inclusive a banda infratermal. Entretanto, Fragal et al. (2011) mostra os benefícios de utilizar os índices de vegetação para classificação como uma técnica muito utilizada e pouco avaliada. Tais índices minimizam o efeito de iluminação da cena, declividade de superfície e geometria de aquisição, permite avaliar a evolução vegetal da área após um determinado fenômeno, entre outros benefícios. 
Desta forma, as técnicas de sensoriamento remoto são importantes, pois permitem conhecer a dinâmica espacial e temporal do local estudado, avaliar o ambiente remotamente, como também alguns produtos são dispostos gratuitamente (FRAGAL et al., 2012), tornando assim um método barato. Neste sentido, por meio dos dados remotos busca-se conhecer tais ambientes, como as planícies de inundação que são de difícil acesso. As planícies fluviais são ambientes complexos e de alta importância devido à biodiversidade do ecossistema, tanto aquático quanto terrestre (AGOSTINHO et al., 1996; FRAGAL et al., 2012).

As planícies de inundação são áreas que transbordam periodicamente, inundando-as, fazendo, assim, com que as espécies presentes se tornem adaptadas a este ambiente (JUNK et al., 1989). Junk et al. (1989) ainda acusa o pulso de inundação como a principal força que controla a biota na planície de inundação, definindo-a como uma força que realiza o processo de inundação de uma planície, ou seja, é o movimento de cheia e vazante de uma planície de inundação. Desta forma, o conhecimento do regime hidrológico é fundamental, já que este controla as espécies pertencentes à planície.

A planície de inundação do Alto Rio Paraná, possui uma grande diversidade de espécies de fauna, flora e ictiofauna, sendo mais de 360 espécies de vegetação e 834 espécies de fauna, e entre eles, vertebrados, mamíferos, aves, repteis e anfíbios, além de possuir cerca de 310 espécies de peixes, os quais contribuem com 7,4 a $8,6 \%$ do número de peixes estimado para região neotropical, mesmo a planície representando apenas $0,4 \%$ do bioma da mata atlântica, este ecossistema possui alta importância para preservação da biodiversidade (AGOSTINHO et al., 1996; AGOSTINHO et al., 2005; AGOSTINHO et al., 2008).

Segundo Souza Filho et al. (2013), o trecho em que a planície do Alto Rio Paraná, pertence é a única região livre de barragens no Rio Paraná, contribuindo assim para sua importância. Com toda esta importância ecológica, no final da década de 1990, criaram-se duas unidades de conservação, a Área de Proteção Ambiental Ilhas e Várzeas do rio Paraná (30/09/1997) e o Parque Estadual das Várzeas do Ivinhema $(17 / 12 / 1998)$.

Contudo, ainda existem impactos a esta área que estão relacionados ao desmatamento da região, como o aumento de solo exposto e efeitos causados a vegetação do local, conforme um estudo realizado por Couto et al. (2011). Além do desmatamento, os diversos tipos de uso da terra realizado pelos habitantes do local, causam impactos a área, como por exemplo, a exploração das áreas turísticas (GALVÃO et al., 2014).

Segundo Rocha (2010), atividades antrópicas como uso da terra para agricultura e desenvolvimento urbano, captação de água do lençol freático para irrigação e abastecimento, construções de barragens para geração de energia, causam alterações no regime hidrológico do rio, quando estes são acumulados às alterações são ainda maiores. O autor ainda revela que qualquer alteração no regime hidrológico, causam sérios impactos nos diferentes biótopos do ecossistema.

Couto et al. (2010) diz que o ecossistema é expressivamente afetado pelas oscilações do nível fluvial, alterando assim o meio físico do local, sendo que a vegetação é um dos elementos constituintes da planície de inundação que mais é afetada pelos pulsos de inundação. Trabalhos realizados por Couto et al. (2010), Couto et al. (2011), Fragal et al. (2012) e Souza Filho et al. (2013) mostram que a vegetação pertencente a 
planície é afetada pelo pulso de inundação. Entretanto, um estudo realizado por Corradini et al. (2006), atribui que a distribuição da vegetação é determinada pelas diferentes altitudes, não destituindo do fato que outros fatores, influenciam na organização destas sobre a planície.

Os estudos realizados na planície do Alto Rio Paraná, descrito pelos autores Couto et al. (2010), Couto et al. (2011), Fragal et al. (2012) e Souza Filho et al. (2013) explicam a influência do pulso de inundação de diferentes anos, sendo a cheia de 1982/1983 descrito por Couto et al. (2010), as cheias de 1976, 1987, 2000 e 2007 por Couto et al. (2011), a do ano de 2007 por Fragal et al. (2012) e Souza Filho et al. (2013) estuda os anos de 1985 a 1994 e 2001 a 2009.

Porém, este último estuda o efeito da construção da barragem de porto primavera sobre a dinâmica da vegetação da planície de inundação, havendo, portanto, uma lacuna de estudo sobre o efeito da grande cheia de 1989/1990. Compilando-se a importância da planície e a necessidade de estudos aprofundados da área, o objetivo deste trabalho é estudar a influência que o pulso de inundação ocorrente nos anos de 1989 a 1990, realiza sobre a dinâmica vegetacional da planície de inundação do Alto Rio Paraná.

\section{MATERIAIS E MÉTODOS}

\section{Caracterização da área de estudo}

A área de estudo encontra-se localizada no sudoeste do estado do Mato Grosso do Sul adjacente ao noroeste do estado do Paraná (figura 1). A planície alagável ocupa uma largura variável entre três e oito quilômetros, presente especialmente na margem direita do Rio Paraná, sendo esta a única região remanescente livre de barragens no rio (SOUZA FILHO et al., 2013), a qual se localiza entre as coordenadas -

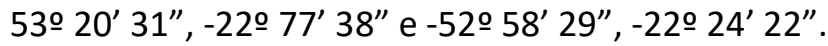

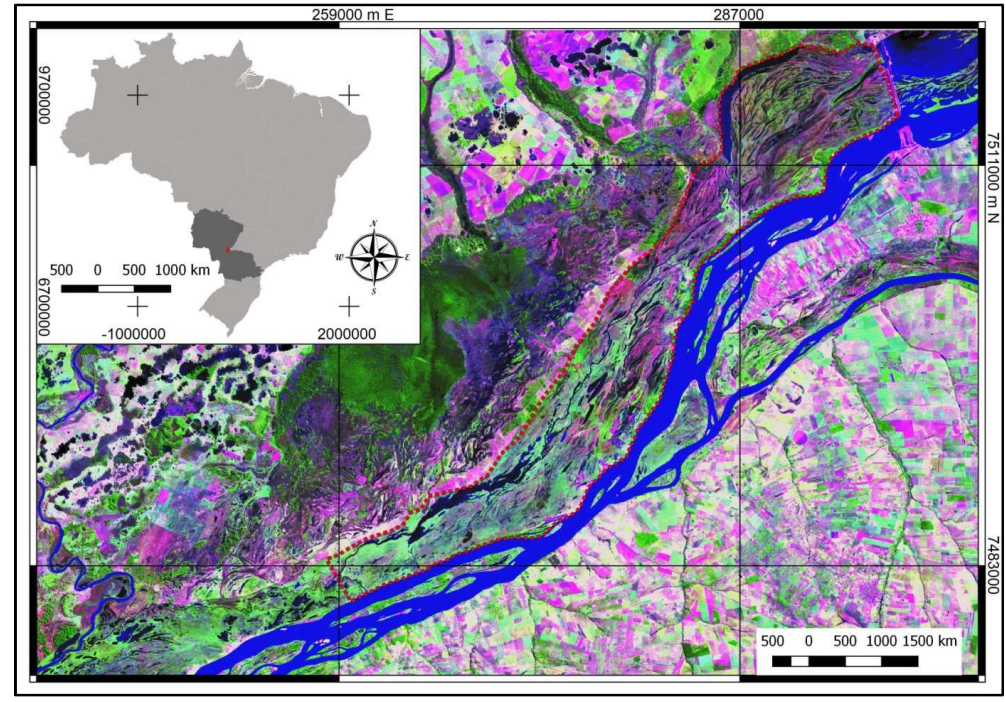

Figura 1: Carta de localização da planície aluvial do Alto Rio Paraná.

Os principais afluentes do Rio Paraná, que tem influência na planície são os Rios Paranapanema e Ivinhema, sendo que o primeiro é controlado pela barragem de Rosana e o segundo possuí um fluxo natural. O fluxo hídrico do rio Paraná é controlado pela barragem de Rosana, e monitorado pela estação fluviométrica de Porto São José situada no rio Paraná, a jusante da foz do rio Paranapanema e a do rio Ivinhema com fluxo 
natural é monitorado pela estação fluviométrica de Ivinhema que está situada no rio homônimo (SOUZA FILHO et al., 2013).

As formas geomorfológicas do local estão em constante transformação, devido à dinâmica fluvial do rio (COUTO et al., 2011). Ainda segundo Couto et al. (2011), o substrato da área é constituído por: depósitos inconsolidados o qual compõe a planície fluvial e pelos arenitos da formação Caiuá. A área é predominantemente plana, com declividade média de $0,18 \mathrm{~m} / \mathrm{km}$ e possuí feições que marcam os canais preferenciais do fluxo hídrico (SOUZA FILHO, 1993; AGOSTINHO et al., 1996).

A região pertence ao domínio da Floresta Estacional Semidecidual Aluvial (IBGE, 1990). E de acordo com Hayakawa et al. (2010) e Couto et al., (2011), a vegetação está fortemente ligada as formas geomorfológicas e assim como estas variam, a vegetação também varia conforme a dinâmica fluvial. A vegetação arbórea está localizada em regiões de altitude média da planície que permanecem secas a maior parte do ano. Já a vegetação higrófila, permanece em regiões mais úmidas e baixas da planície (HAYAKAWA et al., 2010). As herbáceas estão presentes em regiões de acumulação (SOUZA FILHO, 1993). Segundo a classificação feita por Köeppen, o clima da região é Cwa e Cfa (pluvial temperado sempre úmido e com mês seco), (SOUZA FILHO, 1993). Sua temperatura média anual superior a $20^{\circ} \mathrm{C}$ e a precipitação da região são maiores que $1.500 \mathrm{~mm} / \mathrm{ano}$.

\section{Determinação do período de estudo e aquisição das imagens}

Por meio dos dados fluviométricos disponibilizados pela Agência Nacional de Águas (ANA, 2016), foi obtido o histórico das cotas fluviométricas de máximos e mínimos das estações de Porto São José e de Ivinhema, no estado do Paraná e Mato Grosso do Sul, cujos registros são 64.575.003 e 64.617.000. Com base nestes históricos, compôs-se um gráfico a partir das cotas de máximo dos anos de 1985 a 1995. Coincidindo, portanto, com o período da disponibilização das imagens pelo satélite LandSat 5, sensor TM.

Com base no gráfico exposto na figura 2, foi constatada a presença de dez oscilações de cheias e vazantes do rio para a estação de Porto São José. Sendo a maior delas ocorrente no final do ano de 1989 com a cheia e a vazante no início de 1990. Desta forma, este período foi o escolhido para a proposição deste trabalho. A partir dos dados históricos da estação de Porto São José, porém agora para o período proposto, construiu-se um gráfico das cotas fluviométricas dos anos de 1989 e do ano de 1990, obtendo com isso o início exato da cheia e vazante, sendo respectivamente final de novembro de 1989 e final de março de 1990.

Desta forma, foram adquiridas da plataforma Earth Explorer (USGS, 2016) as imagens, cuja cena é 223/76 do satélite LandSat 5 TM, com correção atmosférica, e também se solicitou, junto ao Centro de Ciência de Arquitetura de Processamento EROS (ESPA), os índices de vegetação, tais como: MSAVI, NDVI, NDMI. Para o período entre 31 de novembro de 1989 e 9 de maio de 1990, sendo estas imagens escolhidas para os períodos mais próximos ao anterior a cheia e o pós-vazante que possuíam menos de $10 \%$ de sua cobertura por nuvens. 


\section{Segmentação e classificação das imagens}

As imagens recebidas foram adicionadas em um banco de dados geográficos utilizando o Sistema de Informação Geográfica (SIG) SPRING 5.4 (CAMARA, 1996), onde as imagens foram recortadas para a seleção da área de estudo referente à planície de inundação do alto Rio Paraná. A segmentação de imagem ocorre por conjunto de pixels que são uniformes entre si (COUTO et al., 2011). Dessa forma a segmentação proposta utilizou-se de imagens com os índices de vegetação NDVI, MSAVI e NDMI, selecionando assim diferentes tipos de extratos de vegetação como também as imagens proporcionam o realce da vegetação a qual é o objeto de estudo. A segmentação realizada utilizou-se a similaridade e a área dos pixels de 500 e 15 , respectivamente, para posteriormente coleta das amostras.

Ainda no SPRING 5.4 (CAMARA, 1996) foi realizada a coleta de amostras para cinco tipos de classes, sendo elas: água, solo exposto, vegetação higrófila, vegetação herbácea e vegetação arbórea. Após a coleta das amostras, utilizou-se do algoritmo Bhattacharya para a interpretação das amostras e classificação do uso da terra para toda a planície de inundação do Alto Rio Paraná. Após esta classificação para os períodos analisados, foi quantificado áreas das classes e comparou-se estas, a fim de evidenciar a influência direta da inundação sobre a vegetação.

\section{RESULTADOS}

Na figura 2 verificam-se os períodos de cheia dos Rios Paraná e Ivinhema. A ocorrência deste período em épocas similares é possível, porém o que se verifica é um cenário diferente. Eventos da inundação da planície, evidenciados pela estação fluviométrica de Porto São José, coincidem com as inundações do rio Ivinhema, porém a maioria dos eventos não há esta coincidência. Como na inundação ocorrida nos anos de 1989 e 1990, o qual evidencia que não há sobreposição do pulso de inundação dos rios.

É possível observar ainda a presença de vários picos de inundações ao longo dos 10 anos analisados, entretanto o maior destes chega a um nível de cota fluviométrica de 7,91m, ocorrente no final do ano de 1989 até o início do ano de 1990, enquanto os outros picos ficam em média a 6m de cota, de acordo com a estação fluviométrica de Porto São José.

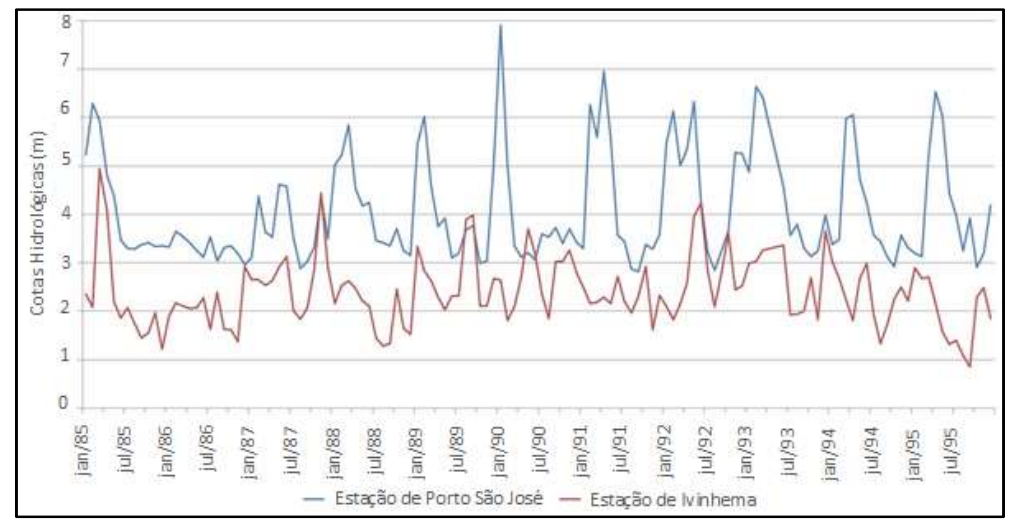

Figura 2: Nível dos Rios Paraná e Ivinhema definido pelas estações fluviométricas de Porto São José (Registro: 64.575.003) e de Ivinhema (Registro: 64.617.000).

A partir do uso e ocupação do solo para os anos de 1989 e 1990, obteve-se: o gráfico com a 
quantificação das áreas das classes em porcentagem (figura 3), o qual representa a variação da cobertura vegetal devido à influência da inundação sobre a planície estudada. A classe que possuiu a maior representatividade para o ano de 1989 foi a vegetação higrófila, enquanto para o ano de 1990 a vegetação herbácea apresentou a maior representatividade. Nota-se que, após a inundação entre os anos, as classes de vegetação higrófila, vegetação arbórea e o solo exposto perderam representatividade, enquanto a vegetação herbácea e a água aumentaram a representatividade, o que demonstra os efeitos do pulso de inundação sobre a paisagem.

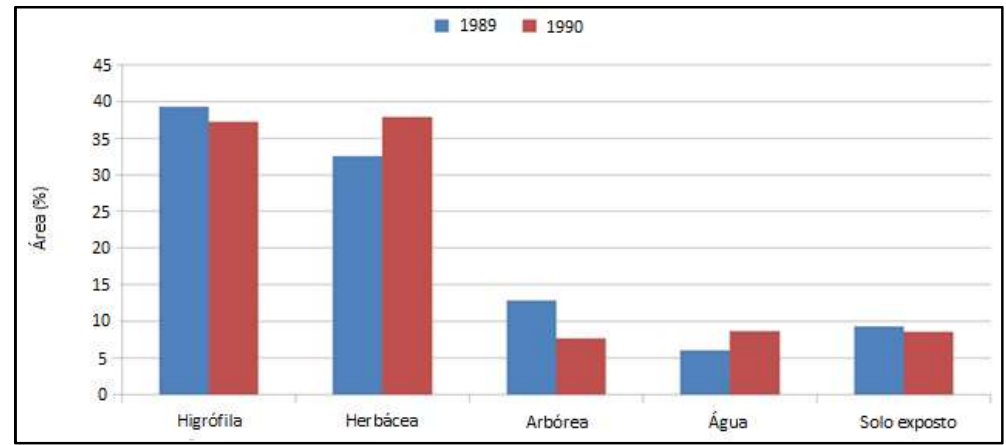

Figura 3: Porcentagem de áreas dos tipos vegetacionais presentes na planície aluvial do Alto Rio Paraná nos anos de 1989 e 1990.

Com base na figura 4, é possível verificar a distribuição das classes de cobertura vegetal ao longo da planície, nos períodos propostos, anterior (A) e posterior (B) à cheia. Na figura $A$, na parte sul da planície de inundação a vegetação arbórea se encontra presente em alguns pontos, porém na figura B após o período da cheia essa região é dominada pela vegetação herbácea, deixando a vegetação arbórea isolada em pequenos fragmentos esparsos entre eles. Além disso, o solo exposto nas figuras apresenta uma diminuição após o período de cheia, com essas áreas sendo tomadas por vegetação.

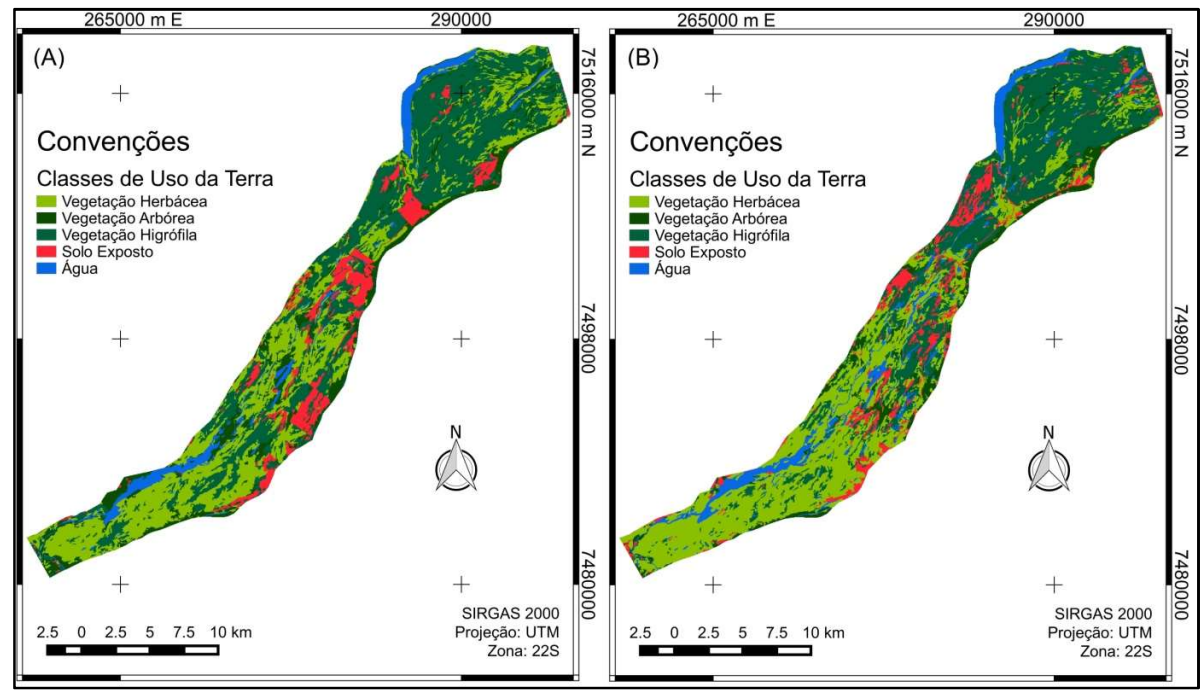

Figura 4: Distribuição das classes de uso da terra sobre a planície aluvial do Alto Rio Paraná, onde (A) representa o ano de 1989 e (B) o ano de 1990.

\section{DISCUSSÃO}

O nível dos Rios Paraná e Ivinhema apresentado na figura 2 por meio dos dados das estações 
fluviométricas de Porto José e Ivinhema, apresentam Segundo Souza filho et al. (2013), o período de cheia dos Rios Paraná e Ivinhema, sendo que o período de cheia do rio Paraná está entre Dezembro e Abril, enquanto que o do rio Ivinhema pode apresentar períodos de cheias durante todo o ano. Com isso, pode ocorrer das cheias dos dois rios coincidirem, porém é mais frequente que esses eventos ocorram em períodos distintos. Porém, Comunello (2001) observa com base nos dados levantados que as cheias com ação combinada dos rios Paraná e Ivinhema são quase tão frequentes quanto as cheias isoladas do Rio Paraná.

O nível fluviométrico do Rio Paraná controlava a área inundada e a soma dos níveis dos dois rios Paraná e Ivinhema controlava a área de vegetação herbácea antes da construção da barragem de Porto Primavera no rio Paraná no ano de 1998, ou seja, para o pulso de inundação ocorrido em 1989/1990 apenas o nível fluviométrico do rio Paraná deve ser levado em consideração (SOUZA FILHO et al., 2013).

Porém, após a conclusão da barragem este cenário foi alterado, desta maneira não existe a possibilidade de uma análise da área inundável da planície fluvial do Rio Paraná considerando apenas o nível fluviométrico da estação Porto José e desconsiderando o nível fluviométrico da estação de Ivinhema, pois o Rio Ivinhema passou a ter influência direta nos pulsos de inundação da planície. Esta intervenção no ciclo hidrológico causado pela construção de barragens, possui ação direta no regime de fluxo do rio (COMUNELLO, 2001; ROCHA, 2002).

A compreensão das áreas atingidas por diferentes níveis fluviométricos é importante para o conhecimento da dinâmica da flora, já que estão ligadas intimamente as mudanças hidrológicas, topográficas e com a umidade dos solos (CORREA, 2002). Além disso, essas variações influenciam tanto no ambiente quanto nas espécies da fauna em seus processos biológicos, como migração, produção e reprodução (ESTEVES, 1998).

Ao analisar as figuras 4 e 5, é possível notar um aumento nas áreas de vegetação herbáceas, principalmente na região sul da planície de inundação, esta ocorrência pode ser justificada, pois após a inundação, a parte sul da planície por ser uma região de baixa altitude, ocorre o acumulo de sedimentos provindos das zonas mais altas, quando ocorre a vazante da planície proporciona condições favoráveis para o crescimento deste tipo de vegetação, por meio dos bancos de sementes.

Segundo Corradini et al. (2006), a distribuição da vegetação ao longo da planície de inundação, está fortemente condicionada a altimetria do local em relação ao rio, já que a dinâmica do rio com os pulsos de inundações, compõe o nível das cheias e a permanência das águas sobre a planície. Contudo, o autor revela que fatores como tipo de solo, fertilidade, distribuição das sementes, saturação de água, resistência à fixação das raízes, entre outros fatores, também contribuí para disposição da vegetação sobre a planície.

O trabalho realizado por Fragal et al. (2012), apresentou que a inundação da planície do alto Rio Paraná, no ano de 2007, também se mostrou uma expansão das áreas de vegetação herbácea, diminuição das áreas de vegetação higrófilas e de solo exposto. Fragal et al. (2012) ainda demonstra que as herbáceas e higrófilas são as mais afetadas pelos pulsos de inundação, especialmente as herbáceas que morrem pela permanência do regime hidrológico de cheia, todavia este tipo de vegetação aumentou após a inundação isto demonstra que a planície já estava se recuperando da inundação pelo processo de sucessão ecológica. 
As áreas de vegetação higrófila, no entanto, diminuíram após a inundação da planície. Após o rebaixamento do lençol freático e a vazante da planície, parte deste tipo vegetacional pode ter morrido devido à falta de áreas úmidas, permitindo assim que a vegetação herbácea ganhe mais espaço e desenvolvase mais nessas regiões. Souza Filho et al. (2013), identificaram que a vegetação higrófila possui alta variabilidade quando os níveis fluviométricos dos rios estão inferiores aos de inundação, contudo também podem desaparecer da planície se os níveis fluviométricos atingirem 9,15m. Dessa forma, como a planície atingiu um nível de $8 \mathrm{~m}$, aproximadamente, é possível que esta diminuição da área de ocorrência deste tipo vegetacional, também pode ter ocorrido devido a elevado encharcamento da área.

Sabe-se que a vegetação arbórea se desenvolve em regiões com altitudes mais elevadas devido à baixa influência dos pulsos de inundação e ocorrência de alagamentos. Conforme exposto por Corradini et al. (2006), a vegetação arbórea desenvolve-se a altitudes de 4 a $5 \mathrm{~m}$ acima do nível do rio. Com isso, quando o nível fluviométrico do rio Paraná atinge cotas superiores a $7 \mathrm{~m}$, este tipo de vegetação é significativamente afetado (ROCHA, 2002; SOUZA FILHO, 2009; FRAGAL et al., 2012).

Houve uma diminuição de 5,20\% da vegetação arbórea na planície, como pode ser observado na figura 4, nota-se que com a ocorrência da inundação (1989/1990), provavelmente a vegetação arbórea tenha ficado com seus troncos submersos em aproximadamente 3 metros. A permanência deste ambiente contribui para a mortalidade das espécies arbóreas, decorrentes do estresse hídrico.

Segundo Couto et al. (2011), a influência da dinâmica fluvial às áreas de corpos de água e áreas úmidas, se dá devido à elevação ou rebaixamento do lençol freático, impedimento do fluxo pelo Rio Baía ou do Rio Ivinhema, ou pelo escoamento mais eficiente destes. Desta forma com o início do processo de inundação eleva-se o lençol freático diminui a capacidade de infiltração da água no solo, aumentando a área com a presença de água, quando ocorre a vazante da planície abaixa-se o lençol freático, aumenta a capacidade de infiltração da água, diminuindo assim as áreas alagadas. Contudo na presente pesquisa, observa-se que ocorreu um aumento na área com a presença de água (figuras 4 e 5), isto pode ter ocorrido, pois após a inundação a planície não conseguiu escoar todo nível fluviométrico elevado, estando ainda em processo de recuperação.

Assim como para Fragal et al. (2012), as áreas de solo exposto após a inundação, diminuíram (figuras 4 e 5). Apesar de após a inundação, parte da vegetação ter morrido divido ao estresse hídrico, o processo de recuperação vegetacional ocorre de forma rápida devido a sucessão ecológica. Porém, devido a diferença entre os anos serem tão baixas, de apenas $0,75 \%$, a diminuição do solo exposto pode ser justificada pelas atividades antrópicas realizadas sobre a planície, como por exemplo a recuperação das pastagens.

\section{CONCLUSÕES}

Com base no exposto, é possível dizer que a inundação na planície do alto rio Paraná, é um evento natural que em geral, estes eventos juntamente com os níveis de descarga do rio provocam modificações na planície, como modificações na vegetação. Todos os tipos vegetacionais são afetados pelos pulsos de inundações, contudo, especialmente as herbáceas e higrófilas, que por ficarem em regiões mais baixas, são 
as primeiras a receberam as modificações do fluxo hídrico. Entretanto, neste trabalho, os principais tipos vegetacionais afetados foram às herbáceas e as arbóreas, com uma diferença de 5,38\% de crescimento para a primeira e de 5,19\% de diminuição da segunda, em relação aos anos de 1989 e 1990. No entanto, todos os tipos de vegetação sofrerem com a inundação, uns aumentando outros regredindo suas áreas de ocorrência, deixando claro, a influência que a inundação causa sobre a dinâmica da vegetação.

\section{REFERÊNCIAS}

AGOSTINHO, A. A.; PELICICE, F. M.; GOMES, L. C.. Dams and the fish fauna of the neotropical region: impacts and management related to diversity and fisheries. Brazilian Journal of Biology, v.68, n.4, p.1119-1132, 2008. DOI: http://doi.org/10.1590/S1519-69842008000500019

AGOSTINHO, A. A.; THOMAZ, S. M.; GOMES, L. C.. Conservation of the biodiversity of Brazil's inland Waters. Conservation Biology, v.19, n.3, p.646-652, 2005. DOI: https://doi.org/10.1111/j.1523-1739.2005.00701.x

AGOSTINHO, A. A.; ZALEWSKI, M.. A planície alagável do rio Paraná: Importância e preservação. Maringá: UEM, 1996.

ANA. Agência Nacional de Águas. Séries históricas. Brasília: ANA, 2016

CAMARA, G.; SOUZA, R. C. M.; FREITAS, U. M.; GARRIDO, J.. SPRING: Integrating remote sensing and GIS by objectoriented data modelling. Computers \& Graphics, v.20, n.3, p.395-403, 1996. DOI: https://doi.org/10.1016/00978493(96)00008-8

COMUNELLO, E.. Dinâmica de inundação de áreas sazonalmente alagáveis na planície aluvial do alto Rio Paraná. Dissertação (Mestrado em Ecologia de Ambientais Aquáticos Continentais) - Universidade Estadual de Maringá, Maringá, 2001.

CORRADINI, F. A.; FACHINI, M. P.; STEVAUX, J. C.. Controle geomorfológico da distribuição da vegetação ripária do rio Paraná: parte I: Unidades geomorfológicas da planície de inundação. GeoCiências, v.5, n.1, p.13-21, 2006.

CORREA, G. T.. Interações mesológicas da vegetação no ambiente ribeirinho Maringá. Tese (Doutorado em Ecologia de Ambientes Aquáticos Continentais) - Universidade Estadual de Maringá, Maringá, 2002.

COUTO, E. V.; HAYAKAWA, E. H.; SOUZA FILHO, E. E.. Diagnóstico dos efeitos causados pelas cheias excepcionais de 1982/1983 sobre a planície inundacional do alto rio Paraná (PR-MS). GEOMAE, v.1, n.1, p.83-99, 2010.

COUTO, E. V.; SOUZA FILHO, E. E.; HAYAKAWA, E. H.. Análise das modificações da cobertura vegetal da planície fluvial do alto rio Paraná no período entre 1976 e 2007 . Acta Scientiarum Technology, v.33, n.2, p.205-213, 2011. DOI: http://doi.org/10.4025/actascitechnol.v33i2.6197

ESTEVES F. A.. Ecophysiological strategies of xerophytic and amphibious plants in the neotropics: Considerations on the ecology of wetlands, with emphasis on Brazilian floodplain ecosystems. Rio de Janeiro: UFRJ, 1998.
FIGUEIREDO, G. C.; VIEIRA, C. A. O.. Estudo do comportamento dos índices de Exatidão Global, Kappa e Tau, comumente usados para avaliar a classificação de imagens do sensoriamento remoto. In: SIMPÓSIO BRASILEIRO DE SENSORIAMENTO REMOTO, 12. Anais. Florianópolis: INPE, 2007.

FRAGAL, E. H.; ALVES, F. C.; SOUZA FILHO, E. E.. A influência da inundação da dinâmica da vegetação da planície fluvial do alto Rio Paraná em 2007. Revista Brasileira de Geomorfologia, v.13, n.3, p.299-310, 2012.

FRAGAL, E. H.; CREMON, E. H.. Catalogação de imagens orbitais a partir da cobertura de nuvem e nível fluviométrico do alto rio Paraná. Boletim de Geografia, v.30, n.3, p.173179, 2012. DOI: http://doi.org/10.4025/bolgeogr.v30i3.17415

FRAGAL, E. H.; SOUZA FILHO, E. E.. Verificação da aplicabilidade dos índices de vegetação para o estudo da identificação vegetal na planície fluvial do Rio Paraná. In: ENCONTRO ANUAL DE INICIAÇÃO CIENTÍFICA, 20. Anais. Ponta Grossa: UEPG, 2011.

GALVÃO, V.; STEVAUX, J. C.; SAAD, A. R.. Análise geoambiental dos ambientes da planície aluvial do alto curso do Rio Paraná: fragilidade e impactos ambientais relativos ao desenvolvimento do uso turístico. GeoCiências, São Paulo, v.33, n.3, p.472-491, 2014.

HAYAKAWA, E. H.; COUTO, E. V.; SOUZA FILHO, E. E.; PRADO, B. R.; PAULA, P. F.. Análise temporal da planície de inundação do alto Rio Paraná (região de Porto Rico-PR) através de dados de sensoriamento remoto. Boletim de Geografia, v.28, n.1, p.115-126, 2010. DOI: http://doi.org/10.4025/bolgeogr.v28i1.8086

IBGE. Instituto Brasileiro de Geografia e Estatística. Geografia do Brasil: Região Sul. Rio de Janeiro: IBGE, 1990.

JENSEN, J. R.. Sensoriamento Remoto do Ambiente: Uma Perspectiva em Recursos Terrestres. São José dos Campos: Parêntese, 2009.

JUNK, W. J.; BAYLEY, P. B.; SPARKS, R. E.. Proceedings of the International Large River Symposium (LARS): The flood pulse concept in river-floodplain systems. Ottawa: 1989.

MARCUSSI, A. B.; BUENO, C. R. P.; MIQUELONI, D. P.; ARRAES, C. L.. Utilização de índices de vegetação para sistemas de informação geográfica. Caminhos da Geografia, Uberlândia, v.11, n.35, p.41-53, 2010.

QI, J.; CHEHBOUNI, A.; HUETE, A. R.; KERR, Y. H.; SOROOSHIAN, S.. A modified sol adjusted vegetation index. 
Remote sensing of environment, v.48, n.2, p.119-126, 1994 DOI: https://doi.org/10.1016/0034-4257(94)90134-1

ROCHA, P. C.. Dinâmica dos canais no sistema rio-planície fluvial do alto Rio Paraná, nas proximidades de porto rico. Tese (Doutorado em Ecologia em Ambientes Aquáticos Continentais) - Universidade Estadual de Maringá, Maringá, 2002.

ROCHA, P. C.. Indicadores de alteração hidrológica no alto Rio Paraná: intervenções humanas e implicações na dinâmica do ambiente fluvial. Revista Sociedade e Natureza, Uberlândia, v.22, n.1, p.191-211, 2010.

RONDEAUX, G.; STEVEN, M.; BARET, F.. Optimization of soiladjusted vegetation indices. Remote Sensing of Environment, v.55, n.22, p.95-107, 1996. DOI: https://doi.org/10.1016/0034-4257(95)00186-7

ROUSE JUNIOR, J. W.; HAAS, R. H.; DEERING, D. W.; SCHELL, J. A.. Monitoring the vernal advancement and retrogradation (green wave affect) of natural vegetation. Greenbelt: NASA, 1974.

SOUZA FILHO, E. E.. Aspectos da geologia e da estratigrafia dos depósitos sedimentares do rio Paraná entre porto primavera (MS) e Guaíra (PR). Tese (Doutorado em Geociências) - Universidade de São Paulo, São Paulo, 1993.

SOUZA FILHO, E. E.. Evaluation of the Upper Paraná River discharge controlled by reservoirs. Brazilian Journal of Biology, v.69, n.2, p.707-716, 2009. DOI: http://doi.org/10.1590/S1519-69842009000300024

SOUZA FILHO, E. E.; FRAGAL, E. H.. A influência do nível fluviométrico sobre as variações de área de água e da cobertura vegetal na planície do alto rio Paraná. Revista Brasileira de Geomorfologia, v.14, n.1, p.81-92, 2013.

USGS. Serviço Geológico dos Estados Unidos. ESPA Ordering. Reston: USGS, 2016.

A CBPC - Companhia Brasileira de Produção Científica (CNPJ: 11.221.422/0001-03) detém os direitos materiais desta publicação. Os direitos referem-se à publicação do trabalho em qualquer parte do mundo, incluindo os direitos às renovações, expansões e disseminações da contribuição, bem como outros direitos subsidiários. Todos os trabalhos publicados eletronicamente poderão posteriormente ser publicados em coletâneas impressas sob coordenação da Sustenere Publishing, da Companhia Brasileira de Produção Científica e seus parceiros autorizados. Os (as) autores (as) preservam os direitos autorais, mas não têm permissão para a publicação da contribuição em outro meio, impresso ou digital, em português ou em tradução. 